http://jmscr.igmpublication.org/home/

ISSN (e)-2347-176x ISSN (p) 2455-0450

crossref DOI: https://dx.doi.org/10.18535/jmscr/v7i10.157

Journal Of Medical Science And Clinical Research

IGM Publication

An Official Publication of IGM Publication

\title{
Incidence of Concha Bullosa in Chronic Sinusitis and Symptomatic Relief following Crushing Turbinoplasty
}

\author{
Authors \\ Vellavedu Umapathy Shanmugam, Thulasi Doss Karunanithi, Prem Nivas, \\ Ruta Shanmugam, Balaji Swaminathan
}

Department of Otorhinolaryngology, Rajah Muthiah Medical College, Chidambaram

\begin{abstract}
Background: The study was conducted with the aim to study the incidence of concha bullosa in chronic sinusitis as detected on computed tomography and to assess the symptomatic relief following crushing turbinoplasty using Kressners turbinate forceps.

Objective: To assess the incidence of concha bullosa in chronic sinusitis. To perform endoscopic crushing turbinoplasty using Kressners turbinate forceps in patients with concha bullosa. To compare pre-operative SNOT-22 score and post-operative SNOT-22 score after crushing turbinoplasty.

Methods: Computed tomography of 100 patients with chronic sinusitis were studied for the presence of concha bullosa. They were categorized into three types: lamellar, bulbous and extensive types. Further graded on diagnostic nasal endoscopic findings. The endoscopic crushing turbinoplasty using Kressners turbinate forceps was done in 15 patients. Patients were regularly followed for a period of 2 months.

Results: The incidence of concha bullosa in chronic sinusitis was found to be $36 \%$. Also, there was significant relief following crushing turbinoplasty with statistical significance $(p<0.05)$.

Conclusion: The incidence of concha bullosa in our study is 36\%. There is statistical significance in the outcome following crushing turbinoplasty.

Keywords: Concha Bullosa, Crushing Turbinoplasty, Kressners turbinate forceps.
\end{abstract}

\section{Introduction}

Sinusitis is inflammation of sinus mucosa (Van Alyea 1963). When symptoms of sinusitis persist for 2 months or more, this is labeled as chronic sinusitis (Lund and Kennedy, 1995). ${ }^{[1]}$ Sinusitis complicates approximately $5 \%$ to $10 \%$ of upper respiratory tract infections. Acute bacterial rhino sinusitis has been defined as sudden in onset and with duration of less than four weeks. Most important cause of chronic sinusitis is failure of acute infections to resolve. Chronic sinusitis is one of the most frequent otorhinolaryngological disease encountered.
Pneumatization of the middle turbinate, the concha bullosa, is one of the most common obstructive anatomic variations in patients with chronic sinusitis. The incidence of positive findings for concha bullosa varies from $14-53 \%$. The incidence of concha bullosa in sinusitis patients was found to be $45 \%$. $^{[2]}$

The aerated middle turbinate may completely fill the space between the septum and the lateral nasal wall thereby blocking the middle meatus and predisposing to sinus infection. Symptomatic concha bullosa needs surgical correction. 
Surgeries commonly done for concha bullosa are complete or partial turbinectomy, partial laminectomy, crushing turbinoplasty, evacuation turbinoplasty. This study attempts to find the incidence of concha bullosa in patients with chronic sinusitis and their relief following crushing turbinoplasty using Kressners turbinate forceps.

\section{Materials and Methods}

Study Design: Phase I- Prospective study, Phase II-Interventional study.

Source of Data: Study was conducted among the patients who underwent Computed Tomographyparanasal sinus for chronic sinusitis in ENT department at Rajah Muthiah Medical College Hospital, Chidambaram during the study period during the period of 2 years from October 2017 to August 2019.

Study Population: The study will be conducted among 100 patients who underwent Computed Tomography of paranasal sinus for chronic sinusitis.
Inclusion Criteria: Patients of age more than 18 years but not more than 50 years with chronic rhino sinusitis

Exclusion Criteria: Patients with nasal polyposis, major surgery or accidents involving the maxillofacial region, uncontrolled Diabetes mellitus, systemic illness like autoimmune disease, neoplastic disease, previous functional endoscopic sinus surgery, immunosuppressants and congenital deformities of the nasal cavity, paranasal sinuses.

\section{Method of Study}

100 patients who were diagnosed to have chronic rhinosinusitis, which was confirmed with CT scan and were included. In phase-I of study, detailed history was taken. Examination of Ear, nose, throat and general examination was done in all the patients. The preoperative symptoms' severity was measured using SNOT-22 score by asking the patient to score according to their symptoms. Anterior Rhinoscopy and diagnostic nasal endoscopy were done in all patients. Endoscopic grading of middle turbinate was done from grade 1 to grade 4 .

Table 1 Endoscopic grading of concha bullosa

\begin{tabular}{|l|l|}
\hline Grade & Description \\
\hline Grade 1 & The sphenoid recess and uncinate process are both clearly visible. \\
\hline Grade 2 & The sphenoethmoidal recess is invisible; the uncinate process is visible. \\
\hline Grade 3 & The sphenoethmoidal recess and uncinate process are both invisible. \\
\hline Grade 4 & Giant concha bullosa occupying the entire middle meatal area, extending to the inferior meatus. \\
\hline
\end{tabular}

The surgery for concha bullosa was limited to was classified into lamellar concha bullosa, patients with grades 2 to 4 concha bullosa in bulbous concha bullosa and extensive / true concha endoscopy. In CT-PNS imaging the concha bullosa bullosa as per Bolger et al classification.

Figure 1 Types of concha bullosa in CT PNS

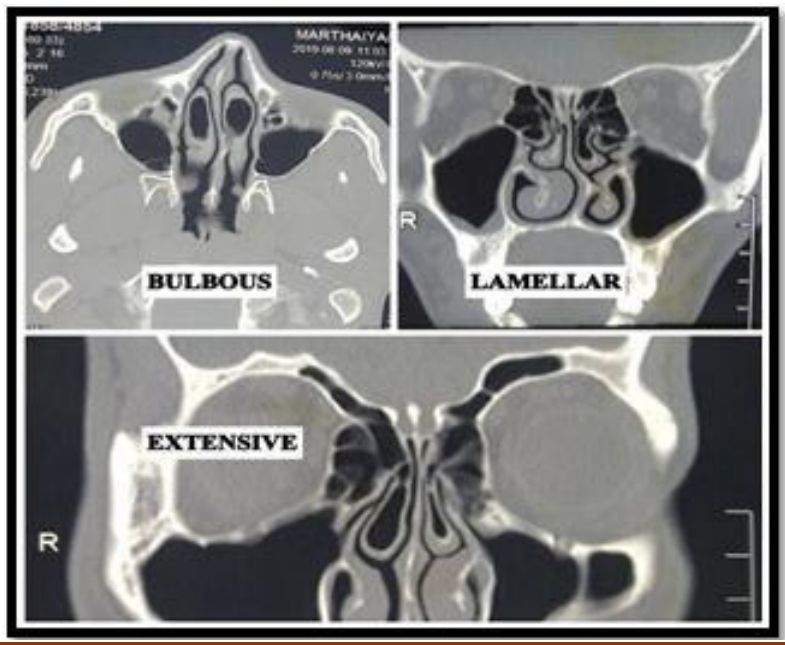


Table 2 Bolger et al classification of concha bullosa

\begin{tabular}{|l|l|}
\hline Type & Description \\
\hline Lamellar type & Pneumatisation of the vertical lamella of middle turbinate. \\
\hline Bulbous type & Pneumatisation of the inferior part of middle turbinate. \\
\hline Extensive type & Pneumatisation of both the vertical lamella and inferior part of middle turbinate. \\
\hline
\end{tabular}

In phase-II study, crushing turbinoplasty was done only for patients with chronic sinusitis and concha bullosa showing minimal mucosal thickening in sinus, no DNS or mild DNS, with absent / minimal inferior turbinate hypertrophy. The endoscopic crushing turbinoplasty using Kressners turbinate crushing forceps was carried out in 15 patients who met the above-mentioned criteria.

Figure 2. Kressners turbinate forceps

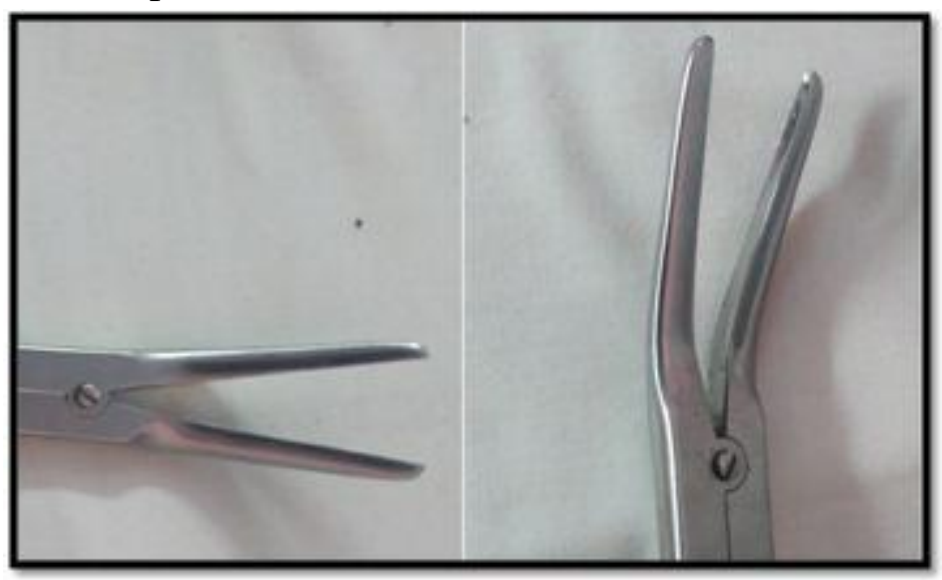

Under general anaesthesia, patient put on supine position, nasal cavities were packed with cottonoids soaked in oxymetazoline and $2 \%$ lignocaine drops. The enlarged pneumatised portion of the middle turbinate was gently crushed between the blades of Kressner turbinate crushing forceps that has a relatively large crushing surface area under rigid $0^{\circ}$ endoscopic view. This was continued inferiorly and posteriorly until adequate visualization of the middle meatus was achieved and middle turbinate was no longer in contact with the lateral wall of nose. This was followed by anterior nasal packing with merocele and removed after 48 hours.

Post operatively parental antibiotics, analgesics, nasal decongestant drops, steroid nasal spray were given for a period of one week. Patients were discharged on 7 th post-operative day with advice of nasal douching along with steroid spray for another 2 weeks. Patient were assessed on post-operative day 2 , day 7 , at the end of 1 month and at the end of 2 months after surgery.

Figure 3 Pre-operative and intra-operative image of concha bullosa
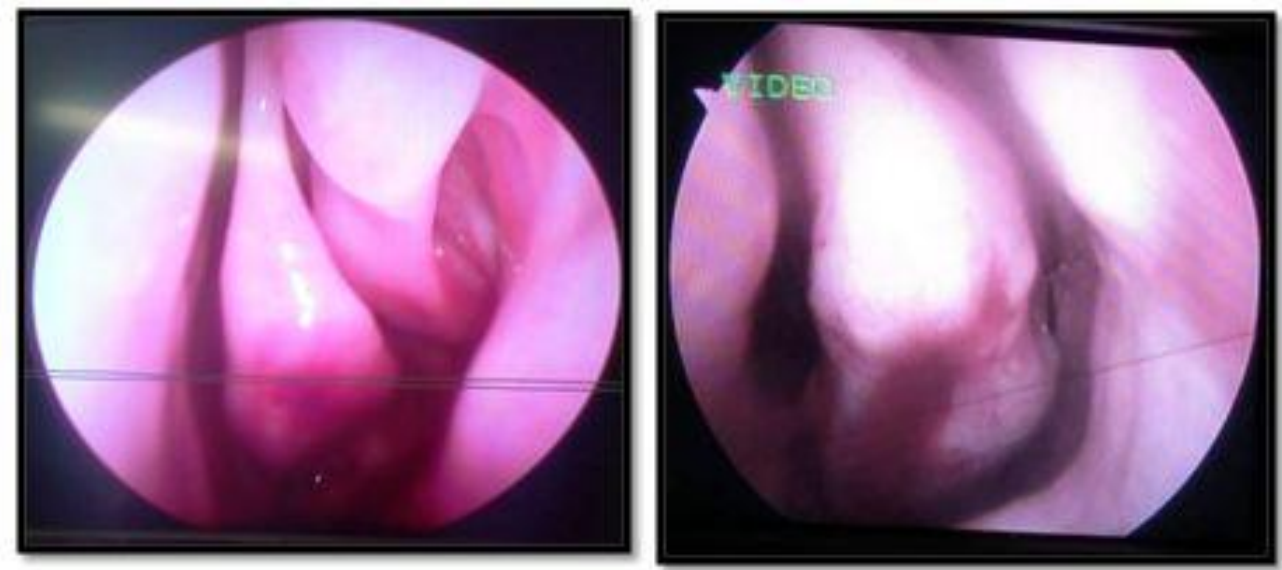
Figure 4. Concha bullosa being crushed between the blades of Kressners turbinate forceps
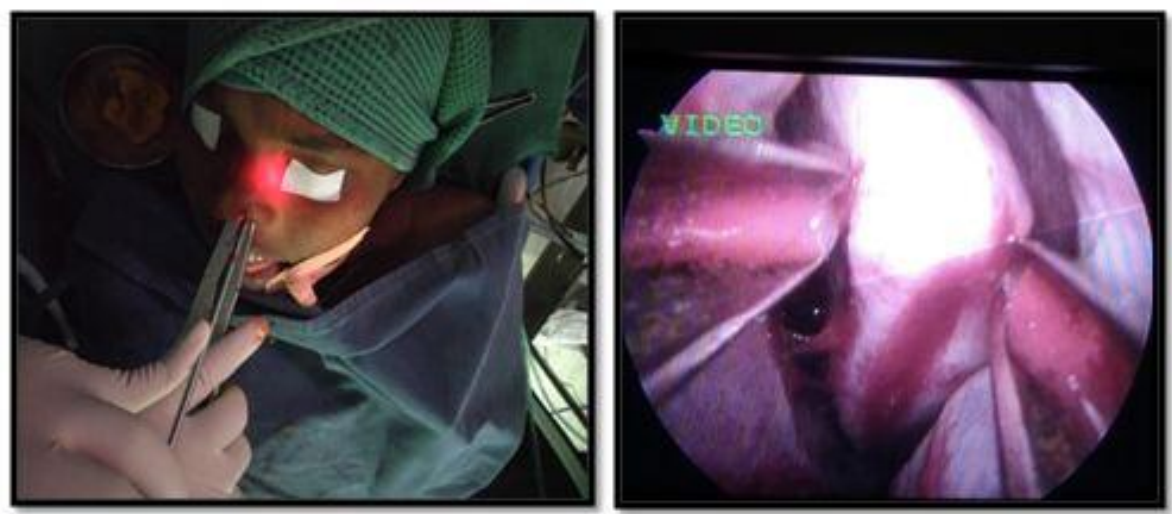

Figure 5. Post-operative endoscopy image
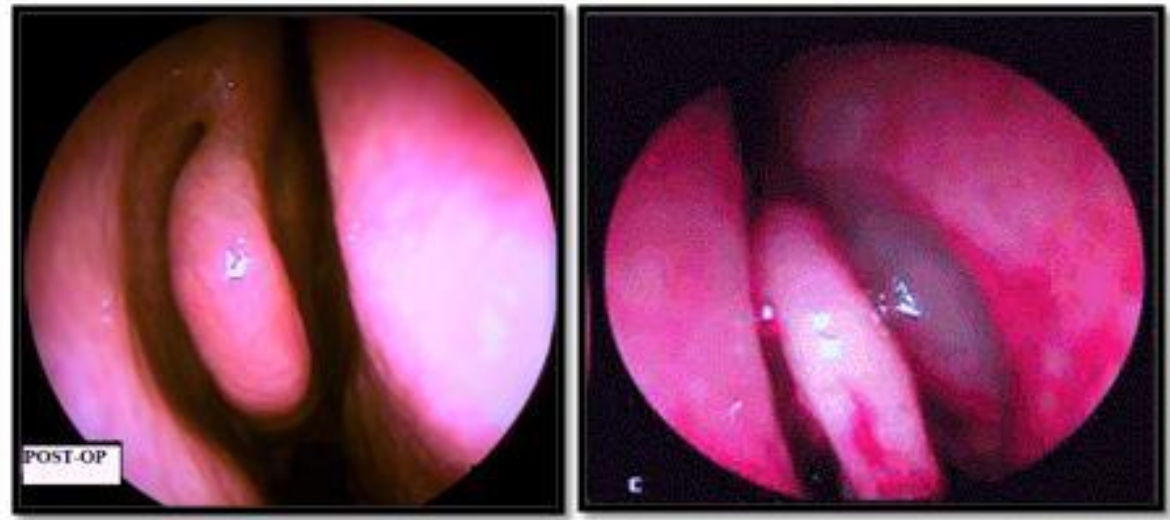

Figure 6 SNOT 22 score

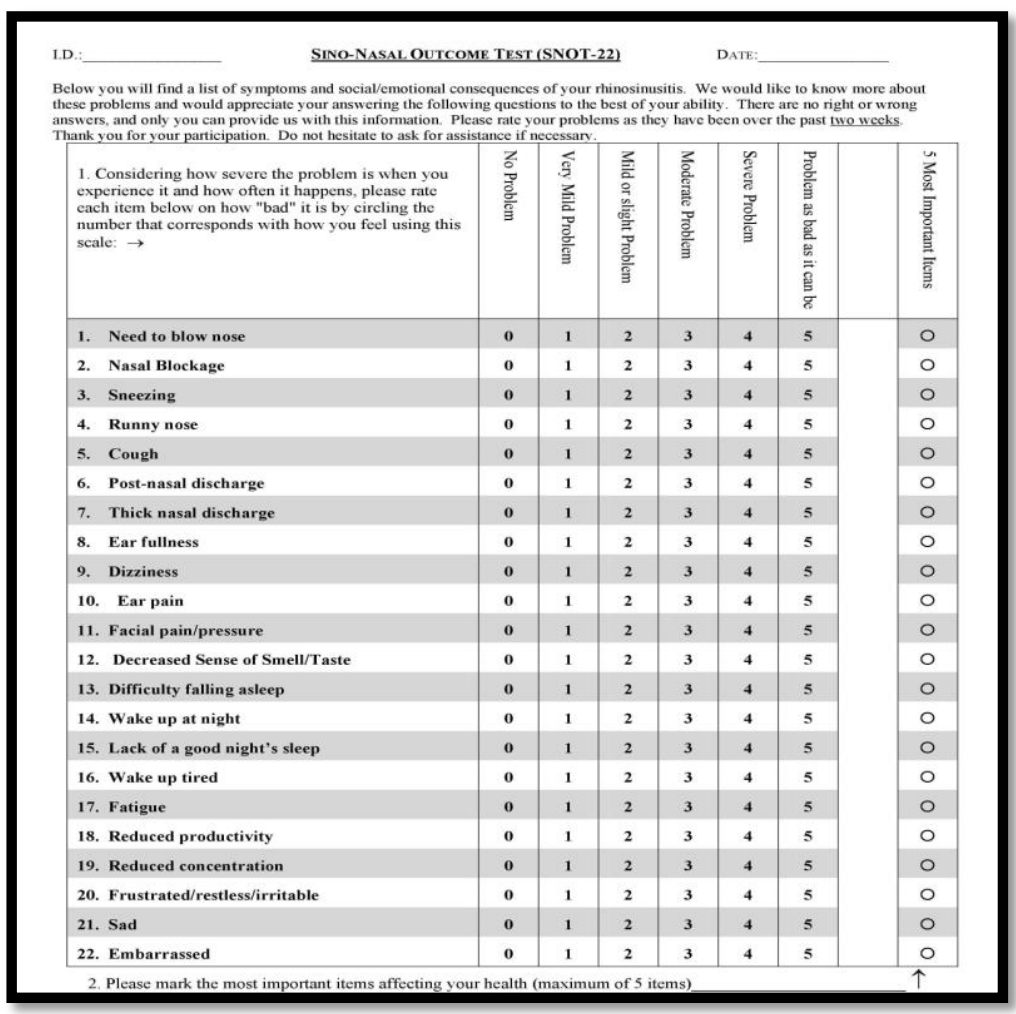

The post-operative SNOT-22 scoring was done pre-operative and post-operative SNOT-22 scores after the end of 2 months of surgery. The assessed were compared and statistically analysed using 
SPSS 16.0 Software. The significance was set at $5 \%$ level of significance $(\mathrm{P}<0.05)$.

\section{Observation and Results}

This study shows that more patients belong to the age group 21-30 years. The mean age of study population is 30.2 years. In the above-mentioned Table.4 and graph.2, the sex distribution of our study population is depicted. There is male predominance $(55 \%)$ in this study.

Table 3: Incidence of concha bullosa in study population $(n=100)$

\begin{tabular}{|l|c|c|}
\hline \multirow{2}{*}{ Concha bullosa } & \multicolumn{2}{|c|}{ Study population } \\
\cline { 2 - 3 } & Number of patients & Percentage \\
\hline Present & 36 & $36 \%$ \\
\hline Absent & 64 & $64 \%$ \\
\hline Total & 100 & $100 \%$ \\
\hline
\end{tabular}

Graph-1. Incidence of concha bullosa in study population

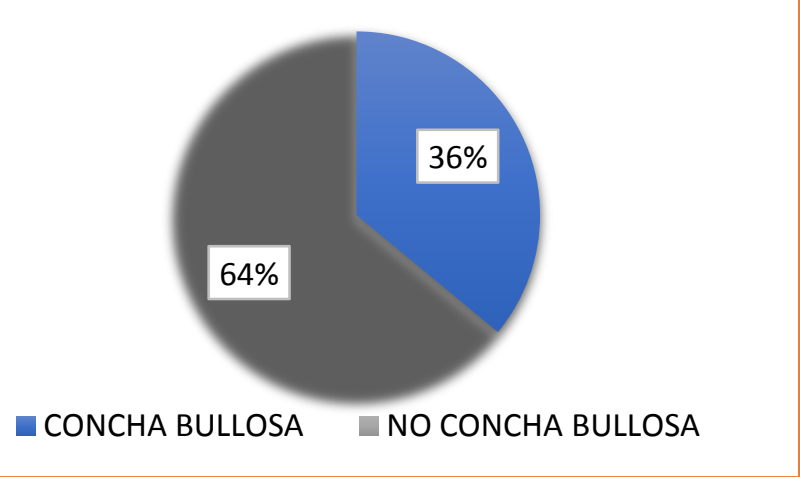

The Table- 3 and graph-1 mentioned above shows that the incidence of concha bullosa in study population is $36 \%$.

Table 4. Incidence of concha bullosa in various age group

\begin{tabular}{|l|c|c|}
\hline \multirow{2}{*}{$\begin{array}{l}\text { Age group } \\
\text { in years) }\end{array}$} & \multicolumn{2}{|c|}{ Concha bullosa } \\
\cline { 2 - 3 } & Number of patients & Percentage (\%) \\
\hline $18-20$ & 3 & $8.33 \%$ \\
\hline $21-30$ & 21 & $58.33 \%$ \\
\hline $31-40$ & 7 & $19.44 \%$ \\
\hline $41-50$ & 5 & $13.88 \%$ \\
\hline Total & 36 & 100 \\
\hline
\end{tabular}

Graph-2. Incidence of concha bullosa in various age group

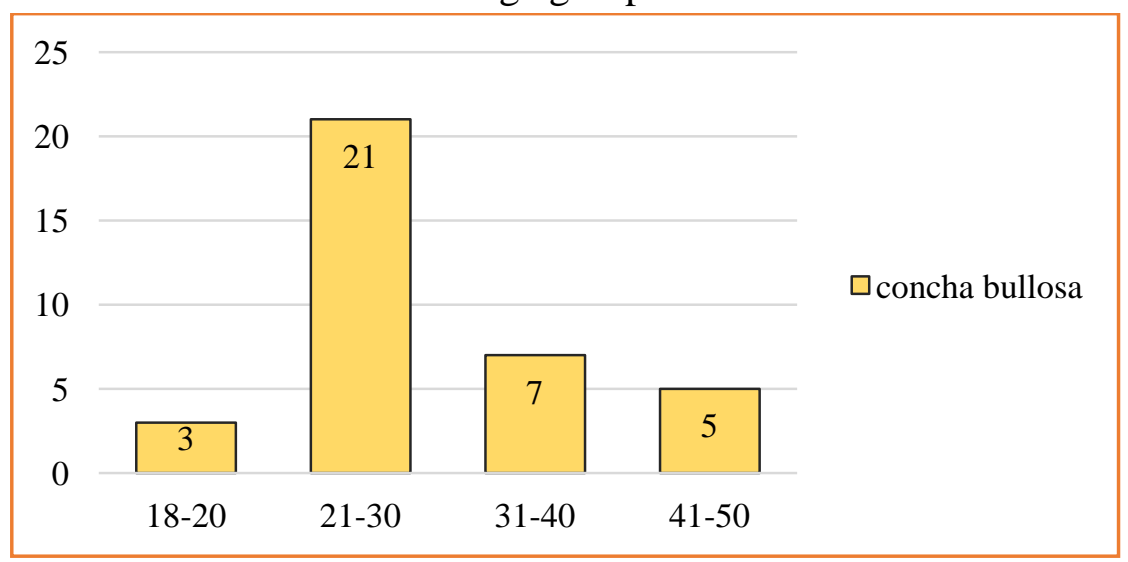


Table .4 and graph 2 shows that in our study, the incidence of concha bullosa is more in the age group 21-30 years $(58.33 \%)$, followed by $31-40$ years $(19.44 \%)$.

Table 5. Sex distribution among concha bullosa patients

\begin{tabular}{|l|c|c|c|}
\hline \multirow{2}{*}{ Sex } & \multirow{2}{*}{$\begin{array}{c}\text { Study } \\
\text { population }\end{array}$} & \multicolumn{2}{|c|}{ Incidence of Concha bullosa } \\
\cline { 3 - 4 } & 45 & Number & Percentage (\%) \\
\hline Female & 55 & 13 & $28.88 \%$ \\
\hline Male & 55 & 23 & $41.81 \%$ \\
\hline
\end{tabular}

Graph-3. Sex distribution of concha bullosa

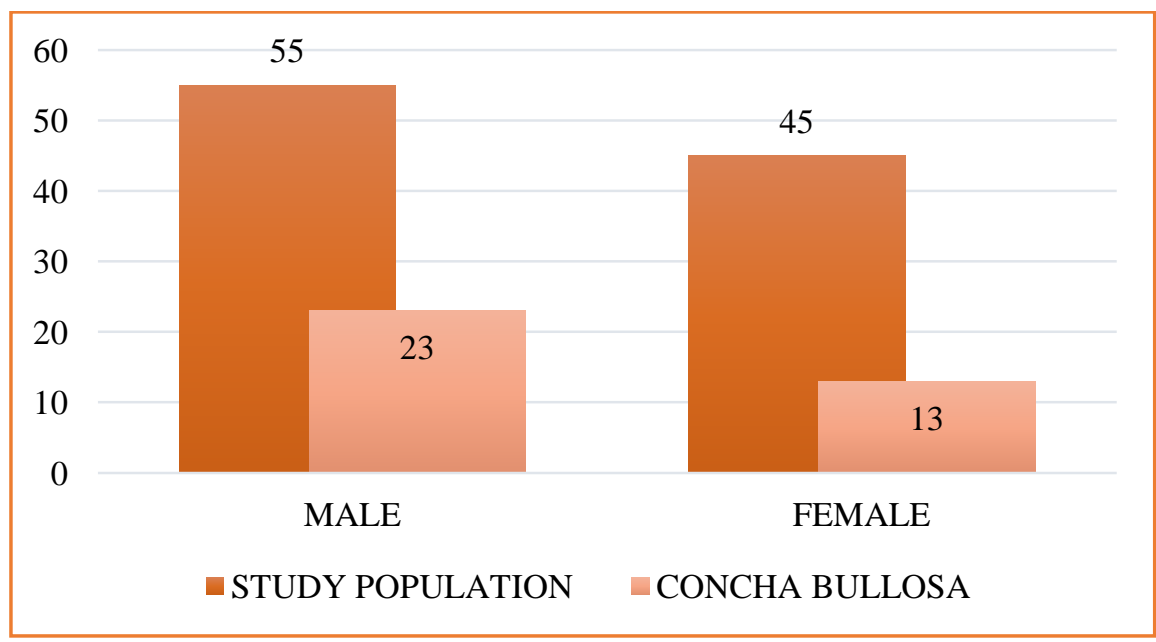

Table .5 and graph 3 shows that in our study there is male predominance $(41.81 \%)$ in the incidence of concha bullosa.

Table 6 Incidence of concha bullosa laterality

\begin{tabular}{|l|c|c|c|c|}
\hline \multicolumn{2}{|l|}{ Concha bullosa } & No. of patients & \multicolumn{2}{|c|}{ Percentage } \\
\hline \multicolumn{2}{|l|}{ Bilateral } & 14 & \multicolumn{2}{|c|}{$38.89 \%$} \\
\hline \multirow{2}{*}{ Unilateral } & Left & 12 & $33.33 \%$ & \multirow{2}{*}{$61.11 \%$} \\
\cline { 2 - 5 } & Right & 10 & $27.78 \%$ & \multicolumn{2}{|c|}{100} \\
\hline Total & 36 & \multicolumn{2}{|c|}{} \\
\hline
\end{tabular}

Graph-4 Incidence of concha bullosa laterality

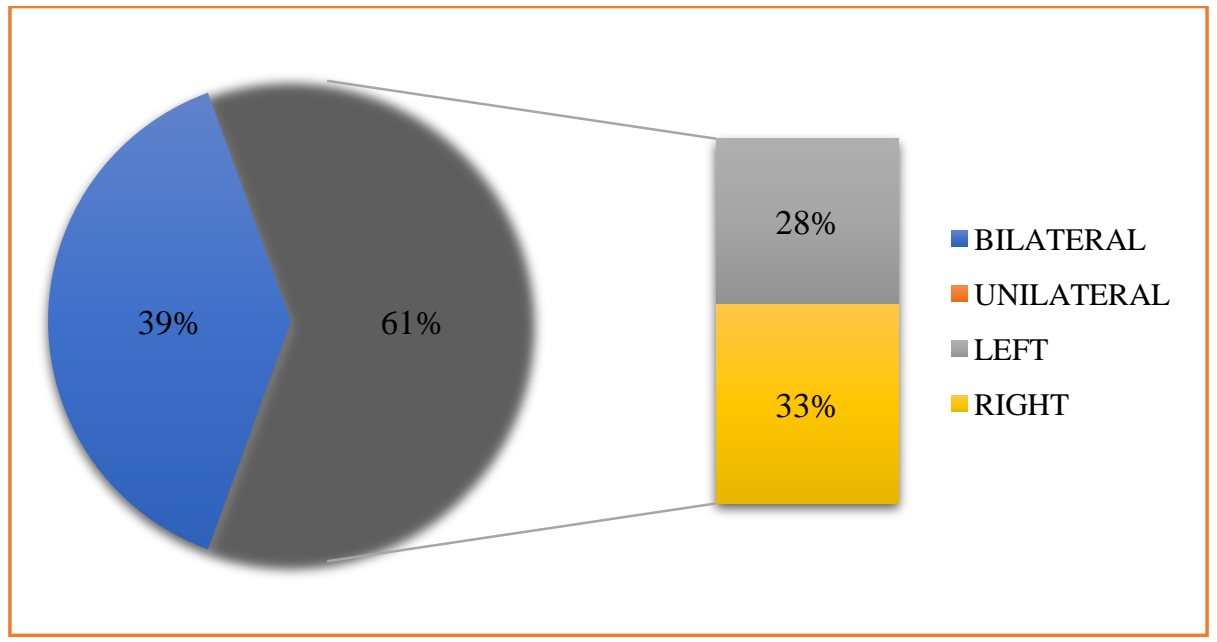

Table. 6 and graph 4 shows that in our study, the unilateral concha bullosa $(61.11 \%)$ is encountered more commonly than bilateral concha bullosa. 


\section{JMSCR Vol||07||Issue||10||Page 913-923||October}

Table 7. Endoscopic grading of concha bullosa

\begin{tabular}{|l|c|c|}
\hline Endoscopic grading & No. of. Patients & Percentage \\
\hline Grade 1 & 8 & $22.22 \%$ \\
\hline Grade 2 & 13 & $36.11 \%$ \\
\hline Grade 3 & 11 & $30.56 \%$ \\
\hline Grade 4 & 4 & $11.11 \%$ \\
\hline Total & 36 & $100.0 \%$ \\
\hline
\end{tabular}

Graph-5. Endoscopic grading of concha bullosa

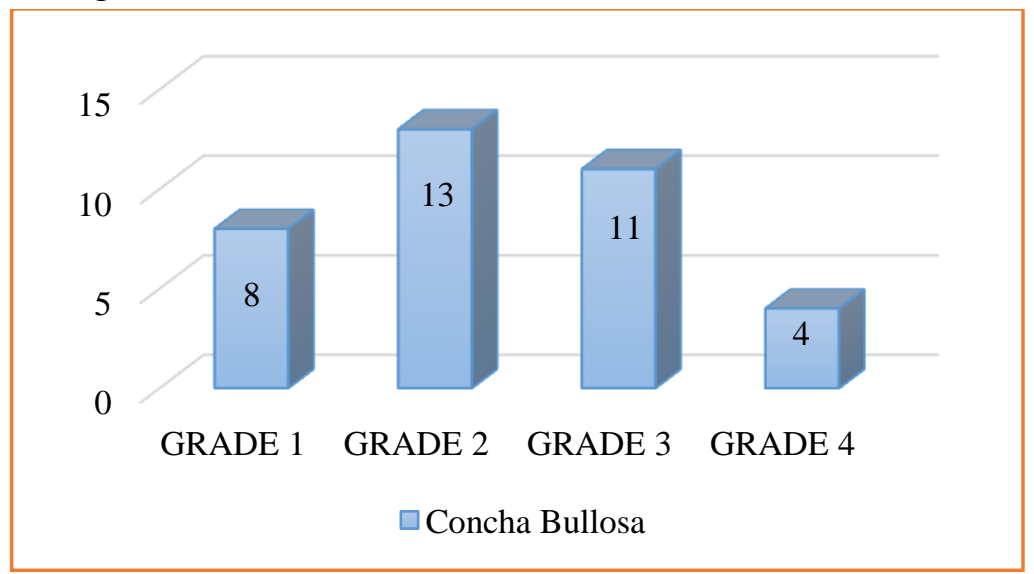

There is higher incidence of grade-2 type of concha bullosa (36.11\%) in our study, as observed from table. 7 and graph-5.

Table 8. Incidence of types of concha bullosa

\begin{tabular}{|l|c|c|}
\hline Type of Concha bullosa & No. of. patients & Percentage \\
\hline Bulbous & 11 & $30.56 \%$ \\
\hline Extensive & 10 & $27.78 \%$ \\
\hline Lamellar & 15 & $41.67 \%$ \\
\hline Total & 36 & $100.0 \%$ \\
\hline
\end{tabular}

Graph-6. Incidence of types of concha bullosa

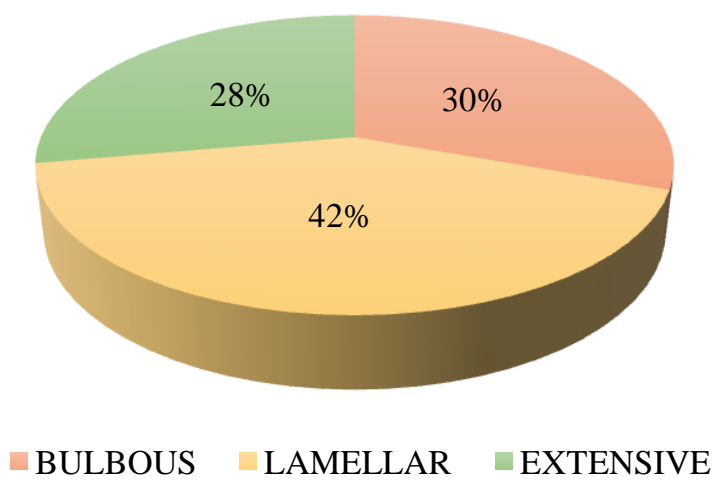

The lamellar type of concha bullosa $(41.67 \%)$ is extensive type of concha bullosa $(27.78 \%)$ as more common in our study population followed by shown by table- 8 and graph- 6 .

bulbous type of concha bullosa (30.56\%) and 
Table 9. Comparison of Pre-Operative and Post-Operative SNOT-22 Score

\begin{tabular}{|l|c|c|c|c|}
\hline SNOT-22 score & Mean & Standard Deviation & 't' value & P value \\
\hline Pre-Op & 48.67 & 3.109 & \multirow{2}{*}{38.483} & \multirow{2}{*}{0.000} \\
\hline Post-Op & 17.07 & 1.100 & & \\
\hline
\end{tabular}

Graph-7. Comparison of Pre-Operative and Post-Operation SNOT-22 Score mean and standard deviation

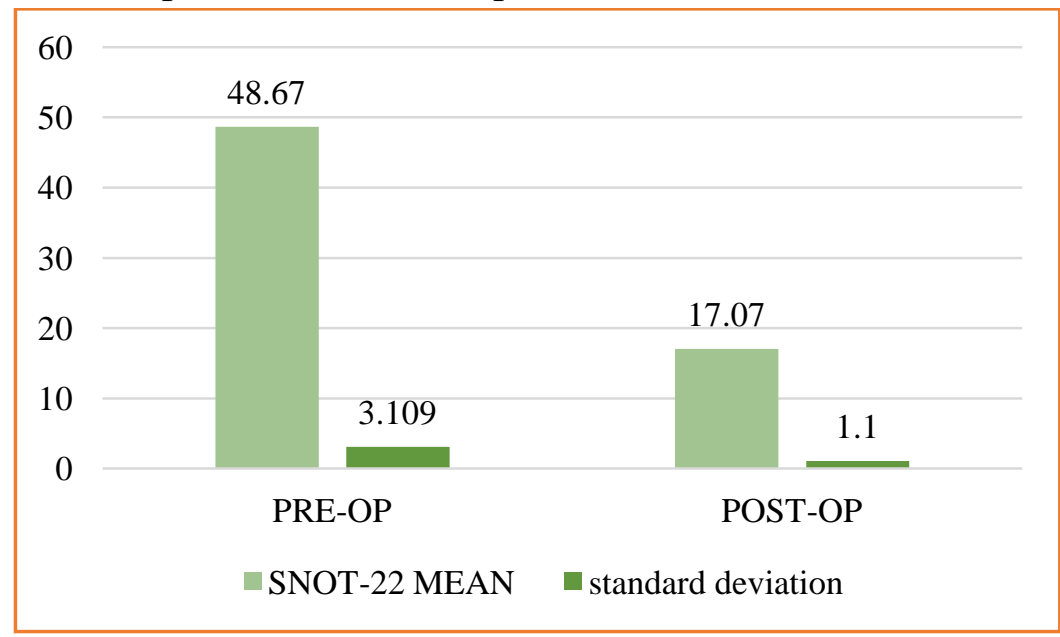

Table-9 and graph-7 shows the comparison between pre-operative and post-operative SNOT-22 score mean. There is appreciable decrease in the post-operative SNOT-22 mean which is statistically significant $(p=0.000)$

\section{Discussion}

The middle concha is embryologically a derivative of medial part of the ethmoid bone. Concha bullosa is the pneumatization of the concha and one of the most frequent variants noted. It is generally seen in the middle concha. It is infrequently found in the superior and inferior conchae. ${ }^{[2]}$ The middle concha pneumatizes almost always from the anterior ethmoidal cells. Pneumatization through the posterior air cells or both occurs but is very rare. Categorization of the pneumatization of the middle concha was first done by Bolger et al into three groups: lamellar type is the pneumatization of the vertical lamella of the concha; bulbous type is the pneumatization of the inferior segment; pneumatization of both the lamellar and bulbous parts is called extensive concha bullosa. ${ }^{[3]}$ Pneumatized middle turbinates sometimes encroach upon the middle meatus, narrow the osteomeatal complex, hinder intraoperative endoscopic access to the middle meatus, and hamper postoperative control of the postoperative bed. Excision of the lateral lamella of the concha bullosa, which is a commonly performed procedure, is associated with reported postoperative adhesions in $15 \%$ of patients especially if the procedure was combined with surgery of the paranasal sinuses. ${ }^{[4]}$ Crushing turbinoplasty has been carried out using various instruments like Pituitary rongeur forceps, Jason Middleton forceps, Freer septal elevator, Dogru forceps, Blakesley forceps and Kressners forceps. The blades of Kressners turbinate forceps has a large surface area and avoids mucosal damage to the middle turbinate. In our study, concha bullosa was treated with crushing turbinoplasty technique using Kressners turbinate crushing forceps. The SNOT-22 tool ${ }^{[5]}$ was used to assess disease specific Quality of Life (QOL) pre-operatively and post-operatively. SNOT-22 scores decreased significantly at the end of follow up period.

In this study, the majority of the study population are between 21-30 years of the age (43\%) and the mean age of the study group is 30.2 years of age. Concha bullosa was commonly identified in the age group between 21-30 years (58\%) and the 
mean age is 29.34 years. Shyamakant Prasad et al observed that the mean age for Concha Bullosa as 28.61 years. $^{[6]}$ Mean age was 38.88 years in $S$ Subramanian et al. ${ }^{[7]}$ Satheesh Kumar Bhandary et al noted that concha bullosa was found commonly in the age group of $21-40$ years $(56.3 \%) .{ }^{[8]}$

In our study, out of 55 male patients 23 had concha bullosa and of 45 female patients 13 had concha bullosa. The male: female ratio was 1.8:1. In Saarthak Wadhwa et al that the male: female ratio was 1:1.6. ${ }^{[1]}$ Shyamakant Prasad et al in their work observed 30 were $(43.47 \%)$ male and $24(47.06 \%)$ were female. The male: female ratio of the study population was $1.4: 1{ }^{[6]}$ Kyle D. Smith et al in their work observed that, of all concha bullosa patients $67.8 \%$ were female patients and $68.3 \%$ were male patients. ${ }^{[10]}$ Sumit Prinja et al observed that out of 50 patients, $54.6 \%$ of male had concha bullosa and $53.5 \%$ of female patients had concha bullosa. ${ }^{[11]}$

Table-10. Incidence of concha bullosa in various literatures

\begin{tabular}{|l|c|c|c|c|c|}
\hline \multirow{2}{*}{$\begin{array}{l}\text { Concha } \\
\text { bullosa }\end{array}$} & \multicolumn{4}{|c|}{ Incidence of concha bullosa in various literature } \\
\cline { 2 - 6 } & Our study & $\begin{array}{c}\text { Saarthak Wadhwa } \\
\text { et al }\end{array}$ & $\begin{array}{c}\text { Shyamakant Prasad } \\
\text { et al }\end{array}$ & $\begin{array}{c}\text { S Subramanian } \\
\text { et al }\end{array}$ & $\begin{array}{c}\text { Safa Saheb } \\
\text { Naji et al }\end{array}$ \\
\hline Incidence & $36 \%$ & $54.28 \%$ & $45 \%$ & $49.5 \%$ & $46 \%$ \\
\hline
\end{tabular}

In this study of 100 patients with chronic sinusitis, the incidence of concha bullosa in concha is $36 \%$. whereas $54.28 \%$ in Saarthak Wadhwa et al ${ }^{[1]}$ study, $45 \%$ in Shyamakant Prasad et al ${ }^{[6]}$ study, $49.5 \%$ in Subramanian et al study. ${ }^{[7]} 41.3 \%$ in $Y . K$. Maru et al ${ }^{[12]}, 40.3 \%$ in Satheesh Kumar Bhandary et al ${ }^{[8]} 44 \%$ in Jamie S. Stallman, $46 \%$ in Safa Saheb Naji et al study. ${ }^{[13]}$

In this study out of 36 patients with concha bullosa, 14 (39\%) had bilateral concha bullosa and 22 $(61 \%)$ had unilateral concha bullosa. Among the 22 patients with unilateral concha, 12 (33\%) had left sided and 10 (28\%) had right sided concha bullosa. Saarthak Wadhwa et al observed that about $54.28 \%$ had concha bullosa on left side, 30\% had concha bullosa on right side and $15.71 \%$ had bilateral concha bullosa. ${ }^{[1]}$ Shyamakant Prasad et al stated that unilateral Concha bullosa were seen in $38.89 \%$ with right side concha in $27.78 \%$, left concha in $11.11 \%$ and bilateral CB in $61.11 \% .{ }^{[6]}$ Safa Saheb Naji et al concluded that $75 \%$ were bilateral, $17 \%$ cases were on the right side and $8 \%$ cases were on the left side.$^{[13]}$

In this study, out of 36 patients with concha bullosa, 11(31\%) patients had bulbous type, 10 (28\%) patients had extensive type and $15(41 \%)$ patients had lamellar type of concha bullosa. Saarthak Wadhwa et al found that 54\% were of lamellar type, $27 \%$ were of bulbous type and $19 \%$ were extensive type. ${ }^{[1]}$ Y.K. Maru et al observed that $45 \%$ had lamellar type of concha bullosa, $29 \%$ had bulbous type of concha bullosa and $26 \%$ had extensive type / true concha bullosa. ${ }^{[12]}$ Raja Kalaiarasi et al study stated that extensive type was in $49.5 \%$, bulbous type in $28.3 \%$ and lamellar type in $22.2 \%$ of patients. ${ }^{[14]} Y$. K. Maru et al observed lamellar type in $42.3 \%$, bulbous type in $27 \%$ and true Concha Bullosa in $30.7 \%$ patients. $^{[15]}$

In the study population, on Endoscopic examination grade 1 concha were seen among $22.22 \%$ ( 8 cases), grade 2 among $36.11 \%$ (13 cases), grade 3 among $30.55 \%$ (11 cases) and grade 4 among $11.11 \%$ (4 cases). Tanyeri et al in his study observed that grade 1 concha bullosa were seen in $13.63 \%$, grade 2 among $31.81 \%$, grade 3 among $45.45 \%$ and grade 4 among $9.09 \%$. ${ }^{[16]}$

In our study, the mean pre-op and post-op SNOT-22 score were 48.67 and 17.07 respectively. Statistical significance was found for crushing turbinoplasty with a $\mathrm{p}$ value of 0.00 . Zayed Mandour et al also observed that there was a drastic decrease in mean SNOT-22 score and was statistically significant following crushing turbinoplasty. ${ }^{[17]}$ 


\section{Conclusion}

- Concha bullosa is a common anatomical variant of lateral nasal wall in patients with chronic sinusitis with an incidence of $36 \%$.

- Crushing turbinoplasty is a minimally invasive technique with a short learning curve and can be made as an effective alternative to other modes of conchoplasty.

- There is a drastic decrease in the post-operative SNOT-22 score following crushing turbinoplasty using Kressners turbinate forceps.

- This crushing turbinoplasty technique using Kressners turbinate forceps is simply to reduce the size of the concha bullosa without many complications. Thus, crushing turbinoplasty for concha bullosa can be preferred as a method for concha bullosa using Kressners forceps can be used as a preferred method for concha bullosa correction without much adverse effects.

\section{References}

1. Saarthak Wadhwa, Naveen Sharma, Uma Garg, Prishni Dutta. Concha Bullosa: Types and Relationship with Chronic Sinusitis. International Journal of Otorhinolaryngology and Head and Neck Surgery. 2017 Jul,3(3):482-485.

2. Harun Dogru, Mustafa Tuz, Kemal Uygur, Meltem Cetin. A New Turbinoplasty Technique for The Management of Concha Bullosa: Our Short-Term Outcomes. Laryngoscope 111: January 2001.

3. Williame Bolger, Clifford A Butzin, David S Parsons.Paranasal Sinus Bony Anatomic Variations and Mucosal Abnormalities; $\mathrm{Ct}$ Analysis For Endoscopic Sinus Surgery. Laryngoscope 101: January 1991.

4. Rabia Shihada, Md; Michal Luntz, Md. A Concha Bullosa Mucopyocele Manifesting as Migraine Headaches: A Case Report and Literature Review. Ear, Nose \& Throat Journal, Volume 91, Number 5, May 2012.
5. Adam S. Deconde, Md1, Jess C. Mace, Mph, Ccrp2, Todd Bodner, Phd3, Peter H. Hwang, Md4, Luke Rudmik, Md, Msc5, Zachary M. Soler, Md, Msc6, And Timothy L. Smith, Md, Mph2. Snot-22 Quality Of Life Domains Differentially Predict Treatment Modality Selection In Chronic Rhinosinusitis - Int Forum Allergy Rhinol. 2014 December; 4(12): 972-979.

6. Shyamakant Prasad, Babita Ahlawat. Ashok Kumar, Sulabha M. Naik, Anil Agarwal, Alka Nagavanshi. Concha Bullosa and Its Association with Chronic Sinusitis. Iosr Journal of Dental and Medical Sciences, Volume 15, Issue2 Ver.1 (Feb 2016). Pp27-32.

7. S Subramanian, Gr Lekhraj Rampal, E.F.M. Wong, S. Mastura, A. Razi. Concha Bullosa in Chronic Sinusitis. Med J Malaysia Vol 60 No 5 December 2005.

8. Satheesh Kumar Bhandary, Shrinath D, Kamath P. Study of Relationship of Concha Bullosa to Nasal Septum Deviation and Sinusitis. Indian J Otolaryngol Head Neck Surg (July-September 2009)61; 227-229.

9. Aruna Kumari AS, Majeed J, Kumar S. Aetiological role of concha bullosa in paranasal sinuses inflammatory diseases. J. Evid. Based Med. Healthc. 2016; 3(86), 4706-4712. DOI: 10.18410/jebmh/2016/991.

10. Kyle D. Smith, Paul C. Edwards, Tarnjit S. Saini And Neil S. Norton.The Prevalence Of Concha Bullosa And Nasal Septal Deviation And Their Relationship To Maxillary Sinusitis By Volumetric Tomography. International Journal Of Dentistry, Volume 2010, Article Id 404982, 5 Pages.

11. Sumit Prinja, Jailal Davessar, Gurbax Singh, Latika Kansal, Jasmine Kaur. Role of Concha Bullosa In Etiopathogenesis Of Chronic Rhinosinusitis: A Clinical Study. International Journal of Contemporary Medical Research 2017; 4(3):774-776. 
12. Y.K. Maru, Yamini Gupta.Concha Bullosa: Frequency and Appearances on Sino nasal Ct. Indian Journal of Otolaryngology and Head and Neck Surgery Vol.52 No.1 December1999- March2000.

13. Safa Saheb Naji.The Incidence Of Ct Scan Finding Of Concha Bullosa In Sinonasal Disease.Medical Journal Of Babylon-Vol. 9- No. 1 -2012.

14. Raja Kalaiarasi, Venkataramanan Ramakrishnan, Santhosh Poyyamoli. Anatomical Variations of The Middle Turbinate Concha Bullosa And Its Relationship With Chronic Sinusitis: A Prospective Radiologic Study.Int Arch Otorhinolaryngol 2018; 22:297-302.

15. Y. K. Maru L, V. Gupta. Anatomic Variations of The Bone in Sino nasal C.T. Indian Journal of Otolaryngology and Head and Neck Surgery Vol. 53 No. 2, April June 2001.

16. Tanyeri H, Aksoy EA, Serin GM, Polat S, Türk A, Ünal ÖF. Will a crushed concha bullosa form again? The Laryngoscope. 2012; 122 (5):956-60.

17. Zeyad Mandour, Remon Kalza And Samy Elwany.A Simple Minimally Invasive Technique to Reduce the Size of Pneumatised Middle Turbinate (Concha Bullosa). Otolaryngol (Sunny Vale) 2016, Volume 6, Issue3. 